\title{
Retrospective analysis of surgical management for spontaneous basal ganglia haemorrhage and outcome: A tertiary institute experience

\author{
Jagminder Singh ${ }^{1}$, Shivender Sobti ${ }^{1{ }^{*}}$, Hanish Bansal $^{1}$, Ashwani Chaudhary ${ }^{1}$, Saurabh Sharma ${ }^{1}$, \\ Vikram Chaudhary ${ }^{1}$ and Tarun Garg ${ }^{1}$
} \\ ${ }^{1}$ Department of Neurosurgery, Dayanand Medical College \& Hospital, Ludhiana, India
}

\begin{abstract}
Background: Spontaneous intracranial haemorrhage (ICH) is the most severe type of stroke with high mortality rates. To provide evidence for clinical practice, here we present a retrospective study to explore the effect of surgery for patients with spontaneous basal ganglia haemorrhage.

Methods: The present study was conducted in the Neurosurgery Department of a tertiary care hospital in the Northern part of India from January 2018 to March 2020. Sixty-one patients aged between 20-70 years of basal ganglia haemorrhage who presented within 24 hours of ictus and operated were included in this study.

Results: A total of 61 patients underwent surgical intervention consisting of 49 (80\%) males and 12 (20\%) females. Their age varied from 27 to 70 with mean age \pm SD $51.93 \pm 13.19$ years. The patients with volume of haematoma 40-60 ml, 82\% patients had GOS 4-5. The patients with midline shift > $5 \mathrm{~mm} ; 78 \%$ patients had GOS 1-3. Patients with midline shift $<5 \mathrm{~mm} ; 82 \%$ had GOS 4-5 ( $\mathrm{P}=0.005)$. The mean hospital stays of unfavourable outcomes group was $28.71 \pm 10.25$ days and of favourable outcomes group was $22.07 \pm 6.32$ days $(0.000)$.

Conclusions: Early surgery (within 6 hours) along with multi-modality medical management has definite positive role in the outcome of patients with spontaneous basal ganglionic haemorrhage. Patients $\geq 50$ years, signs of brain herniation, volume of haematoma $\geq 60 \mathrm{ml}$, hydrocephalic dilatation due the intraventricular haemorrhage, midline shift $>5 \mathrm{~mm}$, and GCS $\leq 8$ at presentation had poor prognosis.
\end{abstract}

Keywords: basal ganglia; spontaneous intracranial haemorrhage; Glasgow coma scale; Glasgow outcome score

*Corresponding author: Dr. Shivender Sobti, MS, MCh., Associate Professor, Department of Neurosurgery, Dayanand Medical College \& Hospital, Ludhiana, India. Tel.: +91 9717489247; Email: sobtish@gmail.com

Received 10 April 2019; Revised 13 June 2020; Accepted 19 June 2020; Published 27 June 2020

Citation: Singh J, Sobti S, Bansal H, Chaudhary A, Sharma S, Chaudhary V, Garg T. Retrospective analysis of surgical management for spontaneous basal ganglia haemorrhage and outcome: A tertiary institute experience. J Med Sci Res. 2020; 8(3):87-93. DOI: http://dx.doi.org/10.17727/JMSR.2020/8-12

Copyright: (c) 2020 Singh J et al. Published by KIMS Foundation and Research Center. This is an open-access article distributed under the terms of the Creative Commons Attribution License, which permits unrestricted use, distribution, and reproduction in any medium, provided the original author and source are credited. 


\section{Introduction}

Spontaneous intracranial haemorrhage (ICH) is the most severe type of stroke with high mortality rates [1]. Approximately, $35-50 \%$ of patients with ICH die within the 30 days after event [2]. The incidence of ICH range from $17 \%$ to $33 \%$ of all strokes, twice as high as in Western countries [3]. Only $12 \%$ to $39 \%$ of the survivors have favourable outcomes $[1,4]$. The mechanisms of brain injury within the cerebral hematoma and the surrounding tissues are complex, which includes the primary effects of blood into the brain parenchyma and the secondary effects from breakdown of blood and its products [5]. Systemic arterial hypertension and cerebral amyloid angiopathy represent the two main risk factors of primary ICH in basal ganglia [6]. The treatment of ICH is still debatable among the neurosurgeons until now. The focus of the controversy is whether evacuation of basal ganglia ICH will be able to improve the prognosis. Some clinical and experimental evidence showed that the removal of ICH might be beneficial for nervous tissue, possibly by relieving local ischemia and removing noxious chemicals [7]. However, the surgical removal of a blood clot within the brain is not risk free. As hematoma involves deep brain structures, a large layer of healthy cerebral tissue needs to be dissected. Additionally, postsurgical complications, such as rehaemorrhages and infections, are not uncommon in this clinical scenario, which increase the rates of mortality and unfavourable outcome [8]. Several studies aiming to explore the efficacy of surgery for patients with ICH had been carried out. However, the results were inconclusive. In STITCH trial (Surgical Treatment for IsCHemic Heart Failure Trial) [9], patients who had presented within 72 hours of ictus were enrolled and patients were randomised into 2 groups; early surgery group (within 24 hours of randomisation) and medical management group and if required were operated later on. In STITCH II trial [10], patients who had presented within 48 hours of ictus were enrolled and were randomised into early surgery (within 12 hours of randomisation) versus conservative group. In our study we have enrolled patients who had presented within 24 hours of ictus. The objective of the study was to find out the surgical outcome in patients who presented within 24 hours of ictus.

\section{Materials and methods}

The retrospective study was started after obtaining approval from Institutional Ethical Committee. The present study was conducted in the Neurosurgery Department of a tertiary care hospital in the Northern part of India from January 2018 to March 2020. Sixty-one patients with basal ganglia haemorrhage were included.

Inclusion criteria were, male and female patients aged between 20 to 70 years with basal ganglia haemorrhage, with or without intraventricular extension within 24 hours post ictus and operated within 6 hours of admission, and with volume of haematoma $40 \mathrm{ml}$ or above, Glasgow Coma Scale (GCS) scores $\geq 5$ and with stable vital signs were included.

Exclusion criteria were the intracerebral haemorrhage caused by secondary factors (e.g., vascular malformations, head injury or coagulopathy), GCS $<5$, multiple intracranial haemorrhage and patients with previous history of intracerebral hematoma or infarct.

Age, sex, neurological assessment, laboratory investigation, radiology and treatment charts were reviewed. CT scan was done on admission in all patients to confirm the diagnosis (Figure 1). The intracerebral hematoma volume was calculated by length $\times$ width $\times$ thickness $/ 2$ in $\mathrm{cm}^{3}$. The mid-line shift over CT scan was measured at the level of the third ventricle.

Stabilization of airway, breathing, and circulation (ABCs) were done to prevent secondary injury from hypoxemia in patients with GCS $\leq 8$. All the patients received evacuation of ICH by well-trained neurosurgeons. In some conditions, an external ventricular drainage (EVD) was inserted before or after the operation. The evacuation of hematoma was assisted by operative microscope and followed the principle of minimal invasiveness. Postoperatively, patients were kept in intensive care unit (ICU) and received medical treatments for decreasing intracranial pressure, blood pressure control, and for deep vein thrombosis prophylaxis. The outcome of all patients were assessed by Glasgow outcome score (GOS) at the time of discharge from hospital. The statistical analysis done by using SPSS software. Student t-test and chi-square test were used. 


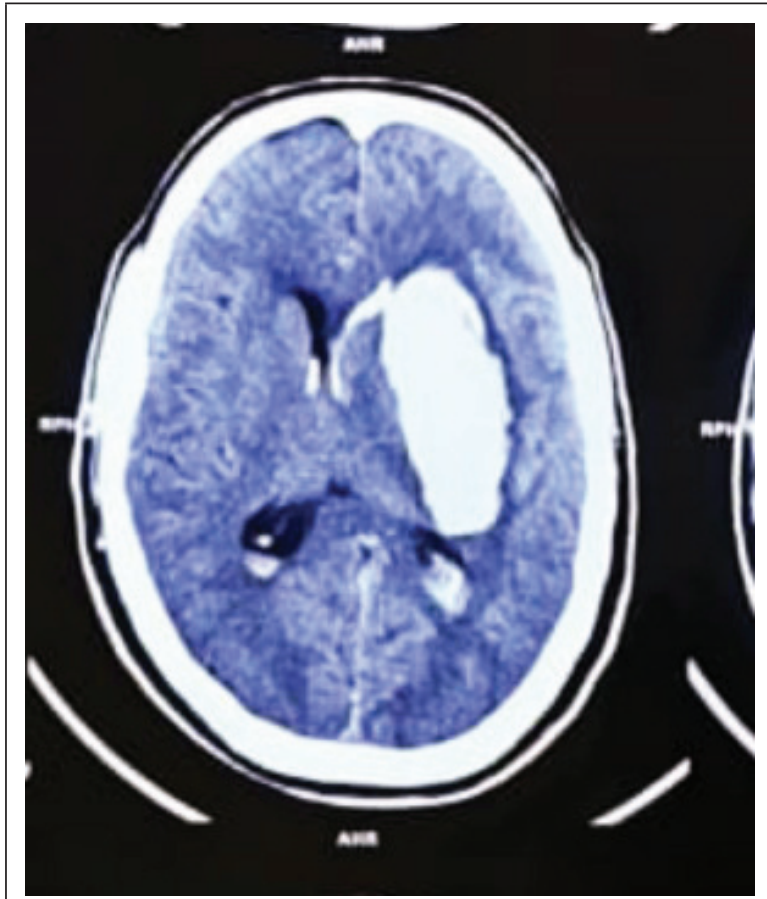

Figure 1a: Preoperative CT scan of left basal ganglia bleed patient with intraventricular haemorrhage.

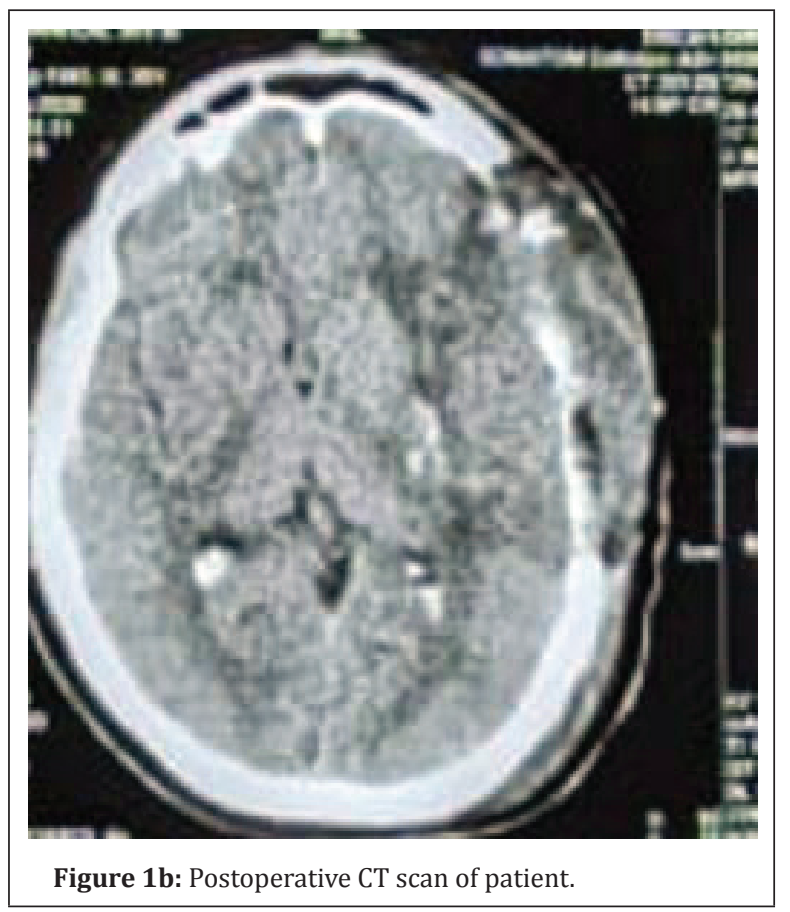

\section{Results}

A total of 61 patients underwent surgical intervention comprising of 49 (80\%) males and 12 (20\%) females. Their age varied from 27 to 70 years with mean age \pm SD $51.93 \pm 13.19$ years. Most patients 20 (33\%) were from 51-60 years age group. There were $15(25 \%)$ patients below 40 years, $10(16 \%)$ patients between 41 to 50 years and $16(26 \%)$ patients above 60 years of age. History of hypertension and diabetes mellitus was present in 39 (64\%) and 19 (31\%) patients respectively. Only $6(10 \%)$ patients were on antiplatelet medication. Patients were distributed according to GCS score at the time of admission into 3 groups: GCS 5-8; 31 (51\%) patients; GCS 9-12; 25 (41\%) patients; and GCS 13-15; 5 (8\%) patients. The volume of hematoma ranged from 40 to $108 \mathrm{ml}$ with mean \pm SD $70.34 \pm 16.39$. Out of 61 patients, 22 (36\%) patients had haematoma volume in the range of 40-60 $\mathrm{ml}, 24(39 \%)$ patients were in range of $61-80 \mathrm{ml}$ and 15 (25\%) patients had $\geq 80 \mathrm{ml}$ of haematoma. Right basal ganglia haemorrhage was in $62 \%$ patients and left side in $38 \%$ patients. Midline shift was $\leq 5 \mathrm{~mm}$ in $21(34 \%)$ and was $\geq 5 \mathrm{~mm}$ in 40 (66\%) patients. Intraventricular haemorrhage (IVH) was present in $9(15 \%)$ patients. EVD was done in 5 patients.

In view of outcomes, 34 (56\%) patients had unfavourable outcomes (GOS 1-3) and 27 (44\%) patients had favourable outcomes (GOS 4-5). In our study, 36 patients were $\geq 50$ years of age, out of which 26 (72\%) patients had GOS 1-3 and 10 (28\%) had GOS 4-5. Whereas out of 25 patients with age $<50$ years, 8 (32\%) patients had GOS $1-3$ and 17 (68\%) patients had GOS 4-5. This difference was statistically significant $(\mathrm{p}=0.005)$.

In our study, 39 patients were hypertensive and 22 non-hypertensives. Among the hypertensives, 24 (62\%) patients had GOS 1-3 and 15 (38\%) patients had GOS 4-5. 10 (45\%) non-hypertensive patients had GOS 1-3 and 12 (55\%) patients had GOS 4-5. The difference was statistically insignificant $(\mathrm{p}=0.225)$. There were 19 diabetic and 42 nondiabetic patients. 10 (53\%) diabetic patients and 24 (57\%) non-diabetic patients had GOS 1-3 while 9 (47\%) diabetic patients and 18 (43\%) non- diabetic patients had GOS 4-5. ( $p=0.743)$. There were only 6 patients on antiplatelet medication, 5 (83\%) patients had GOS 1-3 and 1 (17\%) patient had GOS 4-5. whereas out of 55 patients without antiplatelet medication, 29 (53\%) patients had GOS 1-3 and 26 (47\%) patients had GOS 4-5. This is statistically insignificant $(\mathrm{p}=0.152)$.

Better GCS at the time of admission was an important prognostic factor. There were 31 patients with GCS 5-8. Most patients 28 (81\%) had unfavourable 
outcome (GOS 1-3) and only 6 (19\%) had favourable outcome (GOS 4-5). Out of 25 patients with GCS 9-12; 9 (36\%) had unfavourable outcome (GOS 1-3) and 16 (64\%) had favourable outcome (GOS 4-5). 5 patients (100\%) with GCS 13-15 had favourable outcome (GOS 4-5). The GCS difference among the favourable and unfavourable outcomes were statistically significant $(p=0.000121)$.

In our study, location of haematoma was not related to the outcome of patient $(\mathrm{P}=0.663)$ as right side basal ganglia haemorrhage was present in 23 patients, $12(52 \%)$ had unfavourable outcome (GOS1-3) and 11(48\%) had favourable outcome (GOS
4-5) whereas left side basal ganglia haemorrhage was in 38 patients, 22 (58\%) had unfavourable outcome (GOS1-3) and 16 (42\%) had favourable outcome (GOS 4-5). The volume of the hematoma and extension of hematoma into the ventricular system had significant statistical difference. Out of 22 patients with volume of haematoma $40-60 \mathrm{ml}, 18$ (82\%) patients had GOS $4-5$ and $4(18 \%)$ patients had GOS 1-3. There were 24 patients with volume of haematoma $60-80 \mathrm{ml} ; 16$ (67\%) patients had GOS 1-3 and $8(33 \%)$ patients had GOS 4-5. The volume of haematoma $>80 \mathrm{ml}$ was present in 15 patients, out of which 14 (93\%) patients had GOS 1-3 and only $1(7 \%)$ patient had GOS 4-5. The mean volume

Table 1: Prognostic factors for outcome of surgically treated spontaneous basal ganglia haemorrhage.

\begin{tabular}{|c|c|c|c|c|c|c|c|c|}
\hline \multirow{2}{*}{\multicolumn{2}{|c|}{ Prognostic factors }} & \multicolumn{4}{|c|}{ GOS } & \multirow{3}{*}{$\begin{array}{c}\text { Total } \\
15\end{array}$} & \multirow{3}{*}{$\begin{array}{l}\text { Chi-square } \\
\text { value }\end{array}$} & \multirow{3}{*}{$\frac{p \text {-value }}{0.005}$} \\
\hline & & \multicolumn{2}{|c|}{$\begin{array}{c}\text { 1-3; Number/ } \\
\text { percentage }\end{array}$} & \multicolumn{2}{|c|}{$\begin{array}{c}\text { 4-5; Number/ } \\
\text { percentage }\end{array}$} & & & \\
\hline Age (years) & $<40$ & 3 & $20 \%$ & 12 & $80 \%$ & & & \\
\hline & $41-50$ & 5 & $50 \%$ & 5 & $50 \%$ & 10 & & \\
\hline & $51-60$ & 13 & $65 \%$ & 7 & $35 \%$ & 20 & & \\
\hline & $>60$ & 13 & $81 \%$ & 3 & $19 \%$ & 16 & & \\
\hline \multirow[t]{2}{*}{ Sex } & $\mathrm{F}$ & 6 & $50 \%$ & 6 & $50 \%$ & 12 & 0.199 & 0.655 \\
\hline & M & 28 & $57 \%$ & 21 & $43 \%$ & 49 & & \\
\hline \multirow[t]{3}{*}{ GCS at admission } & $5-8.0$ & 25 & $81 \%$ & 6 & $19 \%$ & 31 & 18.039 & 0.000121 \\
\hline & $9-12.0$ & 9 & $36 \%$ & 16 & $64 \%$ & 25 & & \\
\hline & $13-15.0$ & 0 & $0 \%$ & 5 & $100 \%$ & 5 & & \\
\hline \multirow[t]{2}{*}{ H/O hypertension } & No & 10 & $45 \%$ & 12 & $55 \%$ & 22 & 1.475 & 0.225 \\
\hline & Yes & 24 & $62 \%$ & 15 & $38 \%$ & 39 & & \\
\hline \multirow[t]{2}{*}{$\mathrm{H} / \mathrm{O}$ diabetes } & No & 24 & $57 \%$ & 18 & $43 \%$ & 42 & 0.108 & 0.743 \\
\hline & Yes & 10 & $53 \%$ & 9 & $47 \%$ & 19 & & \\
\hline \multirow[t]{2}{*}{ Antiplatelet medication } & No & 29 & $53 \%$ & 26 & $47 \%$ & 55 & 2.054 & 0.152 \\
\hline & Yes & 5 & $83 \%$ & 1 & $17 \%$ & 6 & & \\
\hline \multirow[t]{2}{*}{ IVH } & No & 25 & $48 \%$ & 27 & $52 \%$ & 52 & 8.384 & 0.004 \\
\hline & Yes & 9 & $100 \%$ & 0 & $0 \%$ & 9 & & \\
\hline \multirow[t]{2}{*}{ MIDLINE shift (cm) } & $<0.5$ & 3 & $14 \%$ & 18 & $86 \%$ & 21 & 22.305 & 0.000 \\
\hline & $>0.5$ & 31 & $78 \%$ & 9 & $23 \%$ & 40 & & \\
\hline \multirow[t]{4}{*}{ Volume of haematoma (ml) } & $40-60$ & 4 & $18 \%$ & 18 & $82 \%$ & 22 & 22.333 & 0.000 \\
\hline & $60-80$ & 16 & $67 \%$ & 8 & $33 \%$ & 24 & & \\
\hline & $>80$ & 14 & $93 \%$ & 1 & $7 \%$ & 15 & & \\
\hline & Left & 22 & $58 \%$ & 16 & $42 \%$ & 38 & \multirow{2}{*}{0.190} & \multirow{2}{*}{0.663} \\
\hline Location of heamatoma & Right & 12 & $52 \%$ & 11 & $48 \%$ & 23 & & \\
\hline
\end{tabular}


of haematoma \pm SD in patients with GOS 1-3 and GOS 4-5 was $77.82 \pm 15.69 \mathrm{ml}$ and $60.93 \pm 11.92 \mathrm{ml}$ respectively $(p=0.000)$. Patients with intraventricular haemorrhage (IVH) also had unfavourable outcome. All the 9 (100\%) patients with IVH had GOS 1-3 $(\mathrm{p}=0.004)$ (Table 1).

The midline shift > 5 mm was in 40 patients, 31 (78\%) patients had unfavourable outcome (GOS 1-3) and 9 (23\%) were with favourable outcome (GOS 4-5). Among the 21 patients with midline shift $<5 \mathrm{~mm}$; $18(82 \%)$ had favourable outcome (GOS 4-5) and $3(14 \%)$ patients had unfavourable outcome (GOS $1-3)$. This was statistically significant ( $p=0.000)$.

The overall mean hospital stays \pm SD was 25.77 \pm 9.34 days. The mean hospital stays \pm SD in 34 (56\%) patients of unfavourable outcomes group was $28.71 \pm 10.25$ days and in 27 (44\%) patients of favourable outcomes group was $22.07 \pm 6.32$ days. That was statistically significant $(p=0.005)$. Three patients died during hospital course. All 3 patients had low GCS at admission (GCS 5-8), large volume of haematoma ( $\geq 80 \mathrm{ml}$ ) with $\mathrm{IVH}$ and midline shift $(\geq$ $5 \mathrm{~mm}$ ) and were comparatively elder in age (mean age $57.18 \pm 10.76$ years)

\section{Discussion}

Haemorrhagic stroke has devastating consequences. Primary ICH is a disease of the elderly. Increasing age is also associated with increased morbidity [11]. The mean age of patients in our study was $51.93 \pm$ 13.19 years. Most of patients 36 (59\%) were $\geq 50$ years age. Several previous studies have shown that older patients with spontaneous ICH experienced the worse outcomes compared with their younger counterparts, including morbidity, mortality and overall quality of life $[1,13,14]$. In our study $72 \%$ patients $\geq 50$ years of age had unfavourable outcome and $28 \%$ had favourable outcome. Our study is in accordance with Van Asch et al. [1] in view of establishing relation of elder age to poor outcome.

Hypertension is the most common risk factor in all the studies related to basal ganglia haemorrhage. A definite history of hypertension was present in $64 \%$ of our patients. The remaining $36 \%$ patients had never undergone a prior medical evaluation and were diagnosed to have raised blood pressure on presentation. This observation was in contrast to the higher rates of pre-existing hypertension
(70-80\%) observed in other studies $[14,15]$. The various studies proposed that diabetes contributes to poor outcome, due to exacerbation of cerebral oedema and cerebral damage. Zheng et al. [16] concluded that hyperglycaemia was associated with poor functional outcome in patients with ICH. In present study $53 \%$ diabetic patient had unfavourable outcome (GOS 1-3) and 47\% diabetic patients had favourable outcome (GOS 4-5). This was statistically insignificant ( $\mathrm{p}=0.743$ ). So, our study's data analysis failed to demonstrate an association between diabetic status and poor outcome. This might be due to lesser number of patients in our study.

We found a statistically significant correlation of level of consciousness at the admission time to the patient's outcome ( $\mathrm{p}$ value $=0.000$ ). In present study, patients admitted with poor GCS (5-8); majority of them (81\%) showed unfavourable outcomes and patients with better GCS (9-12,13-15); 70\% showed favourable outcomes. The finding is in accordance to Lampl et al. [17].

ThevalueofCTscan measurementsin prognostication of ICH is well known [18]. Volpin et al. [19] observed that patients with a hematoma volume above $85 \mathrm{ml}$ have poor outcomes. There were 22 patients with volume of haematoma $\leq 60 \mathrm{ml}$, of these $18(82 \%)$ patients had favourable outcomes and 4 (18\%) patients had GOS 1-3. Out of 24 patients with volume of haematoma $60-80 \mathrm{ml}$; only $8(33 \%)$ patients had favourable outcomes whereas $16(67 \%)$ patients had unfavourable outcomes. In 15 patients the volume of haematoma was >80 ml. Among these 14 (93\%) patients had unfavourable outcomes and only 1 (7\%) patient had favourable outcome. Here, we also found a significant statistical correlation of hematoma size to outcome of patient $(\mathrm{p}<0.000)$. IVH have been found to be strong and independent predictors of poor functional outcome and mortality [20]. In our study, 9 patients were with intraventricular extension, all of them had unfavourable outcome $(\mathrm{p}=0.004)$. This result was statistically significant and in accordance with Diringer et al. [20].

The midline shift signifies the mass effect of ICH and has negative effects on patient's outcome. Patients with a midline shift $\geq 5 \mathrm{~mm}, 78 \%$ patients had significantly unfavourable outcome compared to $86 \%$ patients with a midline shift $\leq 5 \mathrm{~mm}$, who had favourable outcome $(\mathrm{p}=0.000)$. 
The mean hospital stay (28.71 \pm 10.35 days ) was longer in patients elder than 50 years of age, GCS $\leq$ 8 , haematoma volume $\geq 60 \mathrm{ml}$ with intraventricular extension and midline shift $\geq 5 \mathrm{~mm}$ contrary to mean hospital stay $(22.7 \pm 6.32$ days $)$ in patients $\leq 50$ years of age, GCS $\geq 8$, haematoma volume $\leq 60 \mathrm{ml}$ without IVH and midline shift $\leq 5 \mathrm{~mm}$. This was statistically significant with $p$ value 0.005

We enrolled patients who presented within 24 hours of ictus and were operated within 6 hours of admission. In STITCH I [9] and STITCH II [10] trials, patients were enrolled within 72 hours and within 48 hours of ictus and were operated within 24 hours and within 12 hours of randomisation respectively.

In a study done by Suthar et al. [21], most important factors that predicted final outcome were IVH, size of haematoma, midline shift, GCS score and ICH score. Hegde et al. [22] showed elderly age, poor GCS on admission, haematoma volume greater $30 \mathrm{ml}$ and IVH as main negative predictors in South Indian population. In our study, age $>50$ years, haematoma volume $>60 \mathrm{ml}$, IVH, GCS $<8$ are poor predictors of outcome; which is in coherence with the other studies.

\section{Conclusions}

The efficacy of surgery for hematoma evacuation in basal ganglia haemorrhages is still matter of debate. Evacuation should be considered in patients with basal ganglia haemorrhage if there is life threatening mass effect and progressive neurological deterioration. Patients $\geq 50$ years, signs of brain herniation, volume of haematoma $\geq$ $60 \mathrm{ml}$, hydrocephalic dilatation due the ventricular extension of haemorrhage (IVH), midline shift $>5 \mathrm{~mm}$, and GCS $\leq 8$ at presentation have a poor prognosis. Early evacuation of ICH along with multi-modality medical management has definite positive role in the treatment of patients with spontaneous basal ganglionic haematoma. Our study has limitations as sample size of patents was not large enough to provide robust evidence for clinical practice.

\section{Conflicts of interest}

Authors declare no conflicts of interest.

\section{References}

[1] Van Asch CJ, Luitse MJ, Rinkel GJ, van der Tweel I, Algra A, et al. Incidence, case fatality, and functional outcome of intracerebral haemorrhage over time, according to age, sex, and ethnic origin: a systematic review and meta-analysis. Lancet Neurol. 2010; 9(2):167-176.

[2] Nilsson OG, Lindgren A, Brandt L, Säveland H. Prediction of death in patients with primary intracerebral hemorrhage: A prospective study of a defined population. J Neurosurg. 2002; 97(3):531-536.

[3] Stroke epidemiological data of nine Asian countries. Asian acute stroke advisory panel (AASAP) J Med Assoc Thai. 2000; 83(1):1-7.

[4] Mayer SA, Rincon F. Treatment of intracerebral haemorrhage. Lancet Neurol. 2005; 4(10):662-672.

[5] Anderson CS, Huang Y, Wang JG, Arima H, Neal B, et al. Intensive blood pressure reduction in acute cerebral haemorrhage trial (INTERACT): A randomised pilot trial. Lancet Neurol. 2008; 7(5):391-399.

[6] Ariesen MJ, Claus SP, Rinkel GJE, Algra A. Risk factors for intracerebral hemorrhage in the general population: a systematic review. Stroke. 2003; 34(8):2060-2065.

[7] Power C, Henry S, Del Bigio MR, Larsen PH, Corbett D, et al. Intracerebral hemorrhage induces macrophage activation and matrix metalloproteinases. Ann Neurol. 2003; 53(6):731-742.

[8] Flaherty ML, Beck J. Surgery for intracerebral hemorrhage: moving forward or making circles? Stroke. 2013; 44(10):2953-2954.

[9] Broderick JP. The STICH trial: what does it tell us and where do we go from here? Stroke. 2005; 36(7):1619-1620.

[10] Mendelow AD, Gregson BA, Rowan EN, Murray GD, Gholkar $A$, et al. Early surgery versus initial conservative treatment in patients with spontaneous supratentoriallobar intracerebral haematomas (STICH II): A randomised trial. Lancet. 2013; 382(9890):397-408.

[11] Hemphill JC, Bonovic DC, Besmertis L, Manley GT, Johnston SC. The ICH score: a simple, reliable grading scale for intracerebral haemorrhage. Stroke, 2001; 32(4):891-897.

[12] Pinho J, Costa AS, Araujo JM, Amorim JM, Ferreira C. Intracerebral hemorrhage outcome: a comprehensive update. J Neurol Sci. 2019; 398:54-66.

[13] Jolink WMT, Klijn CJM, Brouwers PJAM, Kappelle LJ, Vaartjes I. Time trends in incidence, case fatality, and mortality of intracerebral haemorrhage. Neurology, 2015; 85(15):13181324.

[14] Bhatia R, Singh H, Singh S, Padma MV, Prasad K, et al., A prospective study of in-hospital mortality and discharge outcome in spontaneous intracerebral haemorrhage. Neurology India, 2013; 61(3):244-248.

[15] Narayan SK, Sivaprasad P, Sushma S, Sahoo RK, Dutta TK. Etiology and outcome determinants of intracerebral hemorrhage in a south Indian population, a hospital-based study. Ann Indian Acad Neurol. 2012; 15(4):263-266.

[16] Zheng J, Yu Z, Ma L, Guo R, Lin S, et al. Association between blood glucose and functional outcome in intracerebral hemorrhage: a systematic review and meta-analysis. World Neurosurg. 2018; 114:e756-e765.

[17] Lampl Y, Gilad R, Eshel Y, Sarova-Pinhas I. Neurological and functional outcome in patients with supratentorial hemorrhages: a prospective study. Stroke. 1995; 26(12):2249-2253.

[18] Laissy JP, Normand G, Monroc M, Duchateau C, Alibert E, et al. Spontaneous intracerebral hematomas from vascular causes. Neuroradiology. 1991; 33(4):291-295. 
[19] Volpin L, Cervellini P, Colombo F, Zanusso M, Benedetti A. Spontaneous intracerebral hematomas: a new proposal about the usefulness and limits of surgical treatment. Neurosurgery. 1984; 15(5):663-666.

[20] Diringer MN, Edwards DF, Zazulia AR. Hydrocephalus: a previously unrecognized predictor of poor outcome from supratentorial intracerebral hemorrhage. Stroke. 1998; 29(7):1352-1357.

[21] Suthar NN, Patel KL, Saparia C, Parikh AP. Study of clinical and radiological profile and outcome in patients of intracranial hemorrhage. Ann Afr Med. 2016; 15(2):69-77.

[22] Hegde A, Menon G, Kumar V, Prasad GL, Kongwad LI, et al. Clinical profile and predictors of outcome in spontaneous intracerebral hemorrhage from a tertiary care centre in South India. Stroke Research and Treatment. 2020; 1:1-8. 